\title{
Value-Based procurement for medical devices: A scoping review
}

\author{
Keyvan Rahmani ${ }^{1}$, Saeed Karimi ${ }^{2} *\left(\mathbb{D}\right.$, Reza Rezayatmand ${ }^{2}$, Ahmad Reza Raeisi ${ }^{2}$ \\ Received: 10 Feb 2021 \\ Published: 13 Oct 2021
}

\begin{abstract}
Background: Despite this seemingly simple definition of value in different perspectives, the definition of value-based procurement for medical devices is still unclear. This study aimed to delineate the definition of value-based procurement for medical devices and its characteristics.

Methods: According to the systematic method for scoping review described by Arksey and O'Malley, we reviewed related literature through target databases (PUBMED, ProQuest, Web of Science, Scopus, and Science Direct) during 2004-2020. The publications that focused on the procurement of medical devices and address the issue of value in procurement were selected. The publications whose full-text was not available and were not in English were excluded. By using data charting tables, selected articles were reviewed and concepts and definitions were extracted

Results: According to the eligibility criteria and reference checking, 24 documents were selected. There are different definition and understanding for value-based procurement (VBP). Identified characteristics of VBP are information, actors Collaboration, patient experience, value analysis team, ability to evaluate alternatives, value proposition, competitive dialogue, and weighing evaluation criteria.

Conclusion: VBP is a framework that guides the review and decision-making to procure medical devices. In this framework, all dimensions of the value equation (outcome/related costs) must be considered and weighted. Health systems need to work on identified aspects.
\end{abstract}

Keywords: Value, Value-Based Health Care, Value-Based Procurement, Medical Devices

Conflicts of Interest: None declared

Funding: This study was funded by Isfahan University of Medical Sciences.

\section{*This work has been published under CC BY-NC-SA 1.0 license.}

Copyright $₫$ Iran University of Medical Sciences

Cite this article as: Rahmani K, Karimi S, Rezayatmand R, Raeisi AR. Value-Based procurement for medical devices: A scoping review. Med J Islam Repub Iran. 2021 (13 Oct);35:134. https://doi.org/10.47176/mjiri.35.134

\section{Introduction}

Value-based health care (VBHC), like other health care reforms, has been introduced to address a number of health system challenges, including rising costs and the variation in quality of care $(1,2)$. This concept focuses on health outcomes and their related costs as the value is defined by Porter as health outcomes per dollars spent (3). Among all the factors involved in the process of providing health outcomes, medical devices have the potential to drive $\operatorname{VBHC}(2,4)$, as it is at th e heart of value creation and a tool for value-based transformation in the health

Corresponding author: Dr Saeed Karimi, karimi@mng.mui.ac.ir

1. Department of Health Services Management, School of Management and Medical Information Sciences, Isfahan University of Medical Sciences, Isfahan, Iran

2. Health Management and Economics Research Center, Isfahan University of Medical Sciences, Isfahan, Iran system. Traditional approach in the procurement of medical devices focuses only on the price factor (5). In many countries (developed or less developed), price factor and cost containment continue to play a major role in the procurement of medical devices $(6,7)$.

Price-based approach, which is derived from the shortterm perspective of cost reduction, usually does not take into account the needs of patients and the total costs of acquiring medical equipment $(2,6)$. Focusing solely on the price will result in neglecting the role of different

$\uparrow$ What is “already known" in this topic:

Value-based procurement for medical devices has been an emerging topic in recent years.

$\rightarrow$ What this article adds:

Value-based procurement is a framework that guides the review and decision-making to procure medical devices.

Multi-criteria decision-making is the basis of value-based procurement. 
stakeholders, including patients and providers in the whole process as well as the challenges facing the health system (8). In addition to not considering other factors in the procurement of medical equipment, there is diversity in the procurement process between countries as well as within a country (9). These limitations in the medical device procurement can be seen in the inadequate information system, conflicting incentives, fragmented organizing in procurers, and disqualification of procurers to seek more value $(6,10,11)$.

However, medical devices procurement systems in hospitals and health systems have not been adjusted to overcome this challenge $(2,12,13)$. A shift from a purely price-focused approach to a more comprehensive one with the goal of including the patient outcomes will cause longterm efficiencies and better health for patients $(14,15)$. Studies have shown that a shift to a value-based approach in medical equipment procurement can lead to better health and greater cost-effectiveness in hospital $(5,9,12$, 16). Besides, this approach would be also useful for identifying opportunities for innovation (11). A report showed that some of European countries are moving towards value-based procurement (VBP), albeit at different speeds (17). Thus, VBP would be a key element to unlock valuebased health care (15).

Despite the seemingly simple definition of value in different perspectives (18), the definition of VBP for medical devices is still unclear. Due to the novelty of this concept, there is no common language associated with it, and everyone has interpreted it accordling to their own inference. Accordingly, we decided to answer the following questions through a scoping review of the literature:

1 - What is the definition of VBP for medical devices?

2- What are medical devices VBP characteristics?

\section{Methods}

According to the systematic method for scoping review described by Arksey and O'Malley (19), we reviewed the related literature. The study time frame was from 2004 (as the concept of value in health system was first proposed in 2004 by Michael Porter) to 2020.

\section{Data Sources and Search Strategies}

Target databases for the literature search were the PUBMED, ProQuest, Web of Science, Scopus, Science Direct, and Google scholar databases. The example of search strategy is presented in Table 1. Also, for ensuring comprehensiveness of the search, reference lists of the selected documents and the related websites were also checked.

\section{Study Selection}

Based on the searches, peer-reviewed articles and reports were retrieved for review by researchers. Eligibility criteria are presented in Table 2. The publications that focused on the procurement of medical devices and ad-

Table 1. Example of Search Strategy

\begin{tabular}{|c|c|}
\hline PubMed & 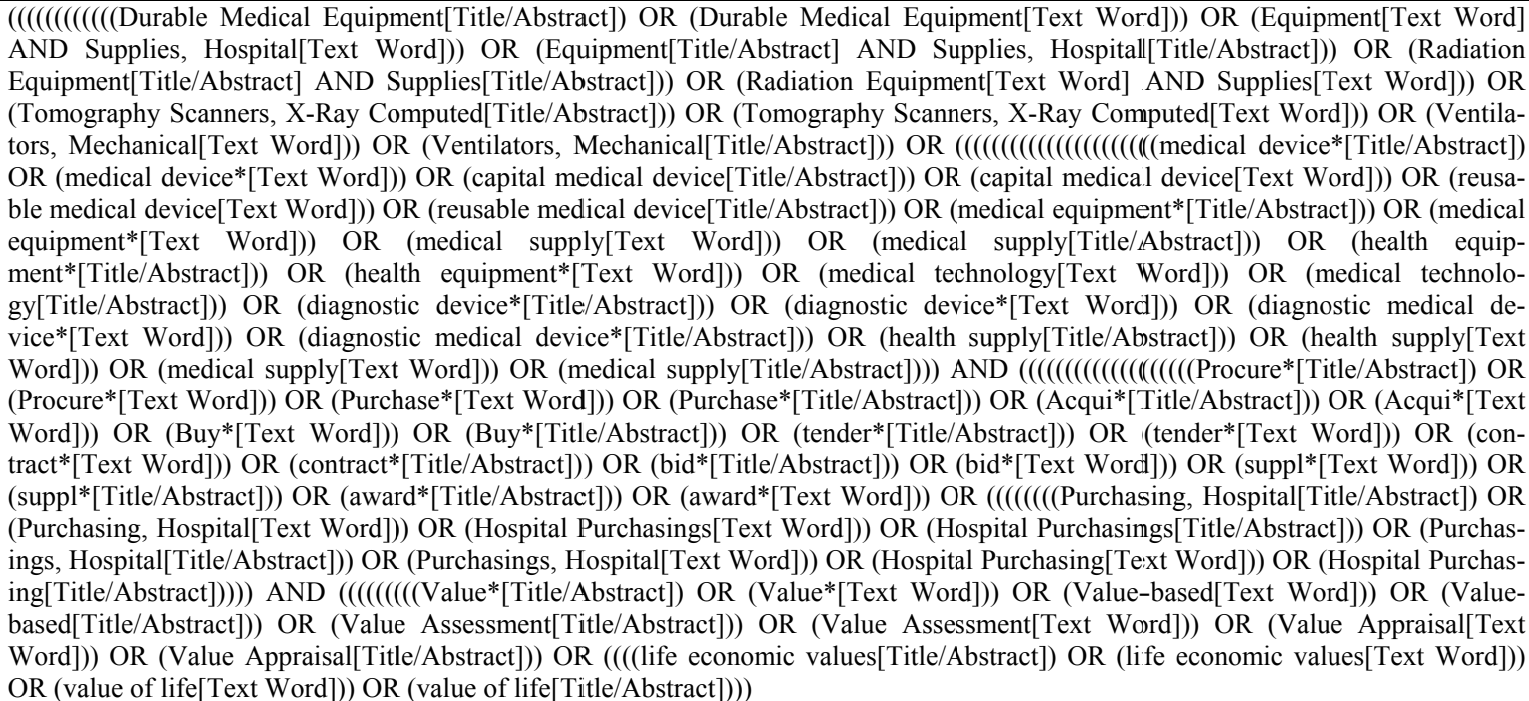 \\
\hline
\end{tabular}

Web of TOPIC: (Value* OR Value-based OR "Value Assessment" OR "Value Appraisal") AND TOPIC: (Procure* OR Purchase*OR Acqui* Science $\quad$ OR contract* OR tender* OR bid* OR supply OR award*) AND TOPIC: (medical device OR medical equipment)

ProQuest (noft(durable medical equipment) OR noft(equipment AND supplies, hospital) OR noft(capital equipment AND hospital) OR noft(radiation equipment AND supplies) OR noft(Tomography Scanners, X-Ray Computed) OR noft(medical device*) OR noft(medical equipment*) OR noft(diagnostic device*)) AND (noft(Purchasing, Hospital) OR noft(hospital purchasings) OR noft(purchasings, hospital) OR noft(hospital purchasing) OR noft(Procure*) OR noft(Purchase*) OR noft(tender*) OR noft(award*) OR noft(contract*) OR noft(bid*)) AND (noft(values of life) OR noft(life economic values) OR noft(Value*) OR noft(value-based) OR noft(value assessment) OR noft(value appraisal))

Science \#1 Medical device OR medical equipment OR medical technology

Direct \#2 Value OR Value-based OR value analysis OR value assessment OR value appraisal

\#3 procurement OR purchasing OR tender OR contract

\#1 AND \#2 AND \#3 
Table 2. Selection Criteria

\begin{tabular}{lll}
\hline $\begin{array}{l}\text { Inclusion } \\
\text { criteria }\end{array}$ & - & Studies on medical devices procurement \\
& - & Value assessment: value-based approach, HTA \\
& - & Available in full text \\
\hline $\begin{array}{l}\text { Exclusion } \\
\text { criteria }\end{array}$ & - & Language: Non-English \\
\hline
\end{tabular}

dressed the issue of value in procurement were selected. The publications whose full-text was not available and were not in English were excluded.

and key issues were identified. The following data were extracted from the selected articles: Author(s) year of publication, origin/country, aims/purpose, type of publication, and key findings. Finally, the definition and attributes of VBP were coded.

\section{Results}

As shown in Figure 1, in total, 2635 articles were retrieved. After exclusion of duplicates $(\mathrm{N}=419)$, the title and abstract screening resulted in 103 articles for full-text screening. According to the criteria in Table 2, after re- viewing the full-texts, 22 articlles were kept for data charting. By reference checking, 2 more documents were added.

The frequency of documents varied during the study period, but in recent years the number of articles and documents in this field has increased and this shows the increasing attention to this approach. Countries that have put VBP on the agenda or implemented it are mostly in Western Europe and North America.

\section{Definition of VBP in Medicall Devices}

Most researchers have considered the procurement of medical equipment equal to the purchasing of medical equipment, while purchasing is part of the procurement

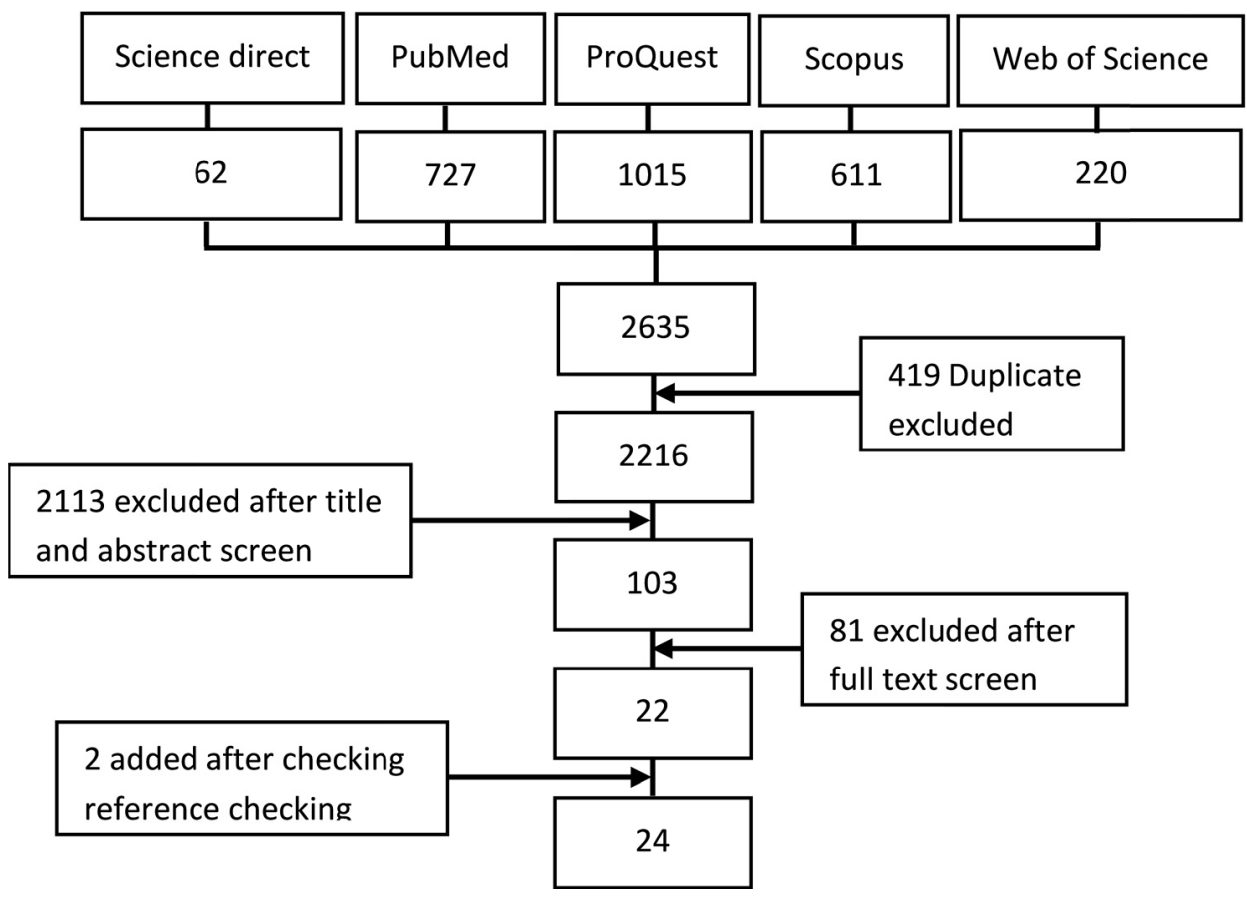

Fig. 1. Stepwise process for selection of papers

Table 3. Summary of Selected Publications

\begin{tabular}{|c|c|c|c|c|c|}
\hline Author(s) & $\begin{array}{c}\text { Year of } \\
\text { Publication }\end{array}$ & $\begin{array}{l}\text { Origin/ } \\
\text { Country }\end{array}$ & Aims/Purpose & $\begin{array}{c}\text { Type of } \\
\text { Publication }\end{array}$ & Key Findings \\
\hline $\begin{array}{l}\text { James C. Robinson } \\
\text { (10) }\end{array}$ & 2008 & USA & $\begin{array}{l}\text { Applies the core principles of value- } \\
\text { based purchasing } \\
\text { To the medical device market }\end{array}$ & & $\begin{array}{l}\text { Core principles of value-based purchasing } \\
\text { are integrated data on price and perfor- } \\
\text { mance; alignment of financial incentives; } \\
\text { and organizational capability to evaluate } \\
\text { alternatives. }\end{array}$ \\
\hline $\begin{array}{l}\text { Christopher D. } \\
\text { Provines (20) }\end{array}$ & 2010 & USA & $\begin{array}{l}\text { To explore organizational barriers of } \\
\text { value-based pricing. }\end{array}$ & Review & $\begin{array}{l}\text { A better understanding of value will help } \\
\text { lead to better investment decisions for the } \\
\text { company and a better spending of our } \\
\text { scarce health-care dollars as a society. }\end{array}$ \\
\hline
\end{tabular}




\begin{tabular}{|c|c|c|c|c|c|}
\hline Author(s) & $\begin{array}{c}\text { Year of } \\
\text { Publication }\end{array}$ & $\begin{array}{l}\text { Origin/ } \\
\text { Country }\end{array}$ & Aims/Purpose & $\begin{array}{c}\text { Type of } \\
\text { Publication }\end{array}$ & Key Findings \\
\hline $\begin{array}{l}\text { Corinna Sorenson, } \\
\text { Panos Kanavosa (6) }\end{array}$ & 2011 & $\mathrm{EU}$ & $\begin{array}{l}\text { To discuss the procurement of } \\
\text { select medical devices across } \\
\text { five countries }\end{array}$ & Review & $\begin{array}{l}\text { A general theme across all national pro- } \\
\text { curement systems was a focus on cost- } \\
\text { containment }\end{array}$ \\
\hline $\begin{array}{l}\text { William T. } \\
\text { Obremskey, Teresa } \\
\text { Dail, } \\
\text { A. Alex Jahangir (16) }\end{array}$ & 2012 & USA & $\begin{array}{l}\text { We describe the challenges, } \\
\text { implementation, } \\
\text { and outcomes of cost reduction } \\
\text { and product } \\
\text { stabilization of a value-based } \\
\text { process for purchasing medical } \\
\text { devices }\end{array}$ & Case study & $\begin{array}{l}\text { The implementation of a facility-based } \\
\text { technology assessment committee that } \\
\text { critically evaluates new technology can } \\
\text { decrease hospital costs on implants and } \\
\text { standardize some product lines }\end{array}$ \\
\hline $\begin{array}{l}\text { Chris Henshall } \\
\text { Tara Schuller (18) }\end{array}$ & 2013 & UK & $\begin{array}{l}\text { Describes some of the key } \\
\text { themes from The Health Tech- } \\
\text { nology Assessment Internation- } \\
\text { al Policy Forum }\end{array}$ & $\begin{array}{l}\text { Round } \\
\text { tables } \\
\text { summaries }\end{array}$ & $\begin{array}{l}\text { Most decision-making systems seek to } \\
\text { take account of similar elements of value, } \\
\text { although they are assessed and combined } \\
\text { in different ways }\end{array}$ \\
\hline $\begin{array}{l}\text { Gerecke G, Clawson } \\
\text { J, Verboven Y (2) }\end{array}$ & 2015 & $\mathrm{EU}$ & $\begin{array}{l}\text { To address healthcare challeng- } \\
\text { es and present new framework } \\
\text { based on new EU directive }\end{array}$ & Report & \\
\hline $\begin{array}{l}\text { Corinna Sorenson, } \\
\text { Michael Drummond, } \\
\text { Lawton R. Burns (21) }\end{array}$ & 2015 & - & $\begin{array}{l}\text { Examines medical device } \\
\text { reimbursement and pricing } \\
\text { policies in the United States and } \\
\text { Europe, with a particular focus } \\
\text { on value }\end{array}$ & Review & $\begin{array}{l}\text { Compared to the United States, Europe } \\
\text { more formally and consistently considers } \\
\text { value to determine which technologies to } \\
\text { cover and at what price, especially for } \\
\text { complex, costly devices }\end{array}$ \\
\hline $\begin{array}{l}\text { Nicolas Martelli, Paul } \\
\text { Hansen, Hélène van } \\
\text { den Brink, Aurélie } \\
\text { Boudard, Anne-Laure } \\
\text { Cordonnier, } \\
\text { Capucine Devaux, } \\
\text { Judith Pineau, Patrice } \\
\text { Prognon, Isabelle } \\
\text { Borget (22) }\end{array}$ & 2015 & France & $\begin{array}{l}\text { To develop a funding decision- } \\
\text { support tool combining MCDA } \\
\text { and mini-HTA, }\end{array}$ & Survey & $\begin{array}{l}\text { The tool could help to promote a more } \\
\text { structured and transparent approach to } \\
\text { HTA decision-making }\end{array}$ \\
\hline Gabriela Prada (15) & 2016 & Canada & $\begin{array}{l}\text { This article presents an over- } \\
\text { view of value within healthcare } \\
\text { systems and how healthcare } \\
\text { value-based procurement is } \\
\text { being implemented across vari- } \\
\text { ous jurisdictions in Canada. }\end{array}$ & $\begin{array}{l}\text { Round } \\
\text { tables } \\
\text { summaries }\end{array}$ & $\begin{array}{l}\text { Strategic, value-based procurement can } \\
\text { be a powerful tool to reinvent the future } \\
\text { of healthicare. }\end{array}$ \\
\hline $\begin{array}{l}\text { Caroline Mosessian } \\
\text { (23) }\end{array}$ & 2016 & USA & $\begin{array}{l}\text { Examines the extent to which } \\
\text { Value Based Purchasing is } \\
\text { being used to } \\
\text { purchase implanted orthopedic } \\
\text { medical devices }\end{array}$ & Survey & $\begin{array}{l}\text { Decisions are commonly, made by com- } \\
\text { mittees and process is still mostly based } \\
\text { on information derived from the clinical } \\
\text { experience } \\
\text { of clinicians and local knowledge of } \\
\text { procurement officers, with less influence } \\
\text { from more formalized health technology } \\
\text { assessments }\end{array}$ \\
\hline
\end{tabular}

process. In the initial definitions of VBP, the use of a more complex process and cost awareness at all stages have been stressed $(10,20)$. Knowing that value is a sum of social and economic effects as well as benefits for the health system in decision making, VBP is a change from the traditional short-term cost savings approach to a more comprehensive approach in which health system performance and patient outcomes as well as the long-term efficiency and effectiveness of decisions are core elements (15). In redefining quality and value with the strategic and VBP approach, the Institute du Québec has identified the patient-centeredness as the key to creating quality in procurement and shifting approach (26). In another definition by the Boston Consulting Group VBP is considered as an approach that takes into account all costs and outcomes in the procurement process (2).

In Italy, researchers have considered the application of economic evaluation methods in the process of procuring medical equipment as VBP. By creating a new indicator (tender score) and combining it with economic evaluation, these researchers have tried to operationalize the concept of $\operatorname{VBP}(5,9,12)$. In another operational definition, VBP is the development of a physician-centered approach and involving physicians' preferences in the provision decisions of medical equipment for patient care (16).

VBP is a decision-making methodology that improves the quality and outcomes of purchasing decisions while maintaining cost control $(11,23)$ and it is possible through setting clinical requirements, cost reduction expectations, and innovation opportunities $(4,14)$. With these 


\begin{tabular}{|c|c|c|c|c|c|}
\hline Author(s) & $\begin{array}{c}\text { Year of } \\
\text { Publication }\end{array}$ & $\begin{array}{l}\text { Origin/ } \\
\text { Country }\end{array}$ & Aims/Purpose & $\begin{array}{c}\text { Type of } \\
\text { Publication }\end{array}$ & Key Findings \\
\hline $\begin{array}{l}\text { Andrea Messori, } \\
\text { Sabrina Trippoli, } \\
\text { Claudio Marinai } \\
\text { (5) }\end{array}$ & 2017 & UK & $\begin{array}{l}\text { To investigate the cost-utility profile } \\
\text { of prostheses for hip replacement and } \\
\text { to calculate a value-based score to be } \\
\text { used in the process of procurement } \\
\text { and tendering for these devices. }\end{array}$ & HTA & $\begin{array}{l}\text { The incorporation of value-based criteria } \\
\text { in the procurement process can contribute } \\
\text { to optimizing } \\
\text { the value for money for THA devices }\end{array}$ \\
\hline
\end{tabular}

Andrea Messori, $2017 \quad$ - $\quad$ This study explored how pharmacoSabrina Trippoli economic models can inform the (12)

Joanne Meehan,

Laura Menzies,

Roula Michaelides

(13)

Heidi Krantz,

BSN,a Barbara

Strain, Jane

Torzewski (24) procurement of TKA devices to improve their value for money.

UK To adopt the resource-based view (RBV) as a lens to explore the extent to which NHS resources support the strategic adoption of value-based approaches

To assess value analysis process in procurement of Medical device innovation
HTA

Empirical

case study

Case study

ideration of

the degree to which the product or a potentially new innovative idea improves patient c:are and patient satisfaction is also part of the decision-making process, but other financial concerns and a value-based analysis do and will play an important part in this decision.

To explored using pharmacoeconomic models in the in-hospital procurement of thrombectomy devices.

Erminia Caccese

Claudio Marinai,

Andrea Messori

(9)
Kull S, Atanasov

P, Jonas N (14)

Bruce Campbell

Mark Campbell

Lee Dobson

Joanne Higgins

Bernice Dillon

Mirella Marlow

(25)

Federico Pennestrì

2019

Italy

To introduce VBP from a theoretical and an empirical level, referring to relevant practices and challenges which emerged in the current institutional, clinical and academic debate

Giuseppe Ba

(11)

Fiona A. Miller, 2019 Canada To have detailed analysis of how procurement approaches the decision task

To assess the impact of evidencefocused policy changes on the availability of clinical evidence for medical devices and their use in purchasing.

e Lehoux,

Stuart Peacock,

Valeria E. Rac,

Jeff Neukomm,

Carolyn Barg,

Jessica P. Bytautas

and Murray Krahn
Tove a detailed scrutiny of claim the corresponding evidence made for the benefits of products and
HTA

Bridging the methodology of costeffectiveness with the every-day practice of in-hospital procurement can contribute to maximizing the health returns that are generated by in-hospital expenditures for medical devices.

Structured Across all EU countries, the median use review of of MEAT vs. lowest price tender award clinical criteria increased from $49 \%$ before to $69 \%$ trials after 2014 .

Documents It illustrates the importance of relevant review evidence and of having a clear vision of the place of new products in care pathways from an early stage

Review When different dimensions of value are supported by well-designed study to identify the respective outcomes, it becomes healthcare quality and sustainability

Document While aiming to go beyond price in the review acquisition of most medical technologies, it adopts a narrow approach to assessing quality and costs, but also attends to factors little considered by HTA easier to find better solutions in support of definitions, Krantz seems to have provided the most comprehensive definition: "making deliberate choices on what products and services are needed to provide best-in-class care at an affordable cost through a framework that guide the review and decision-making processes by analyzing the cost and clinical outcomes expected from the use of that product or equipment in the care of patients." (24) The results of analysis of selected articles in understanding the definition of VBP in medical devices are shown in Table 3. 


\section{VBP Characteristics}

Changing the paradigm of medical equipment procurement in health systems must be accompanied by a clear and definite framework $(4,22)$. Using the best practices and models and combining them in a way that is methodologically easy and reliable can be very useful in this development $(9,22)$. The comprehensiveness of evaluation criteria in the procurement process and their classification with a view to creating value can reflect the concerns of health system policymakers and decision makers. In the EU, the 2014 Directive has been positive in the use of VBP and the shift towards patient outcomes and valueadded supplements, although this effect has not yet been widespread (14).

The new approach to medical equipment procurement should be user-friendly, simple, and reliable. In selected studies, researchers have each pointed to the characteristics and principles of VBP. Although these features have a wide range in appearance, in practice they have a lot of overlap (Table 4).
The dimensions and characteristics identified for VBP in medical devices (Table 5) are described below and their importance is also noted.

\section{Information}

Information is the heart of VBP and the cornerstone of decision-making in most studies. Information means analyzing data on working devices, new technology, costs for similar devices, total cost of acquisition, the incentives of the key actors, and organizational capability $(2,10,16$, 23-25). Medical devices information shortages are not only seen in performance information but also in costs associated with it (10). In fact, the scientific evidence for medical devices is limited due to number of reasons, including low regulatory requirements and limited financial resources, to produce evidence (25). We need standard and transparent information in all areas (16) and this information must be strong and comparative to make resilient and effective decisions (23).

Table 4. The Definition of VBP

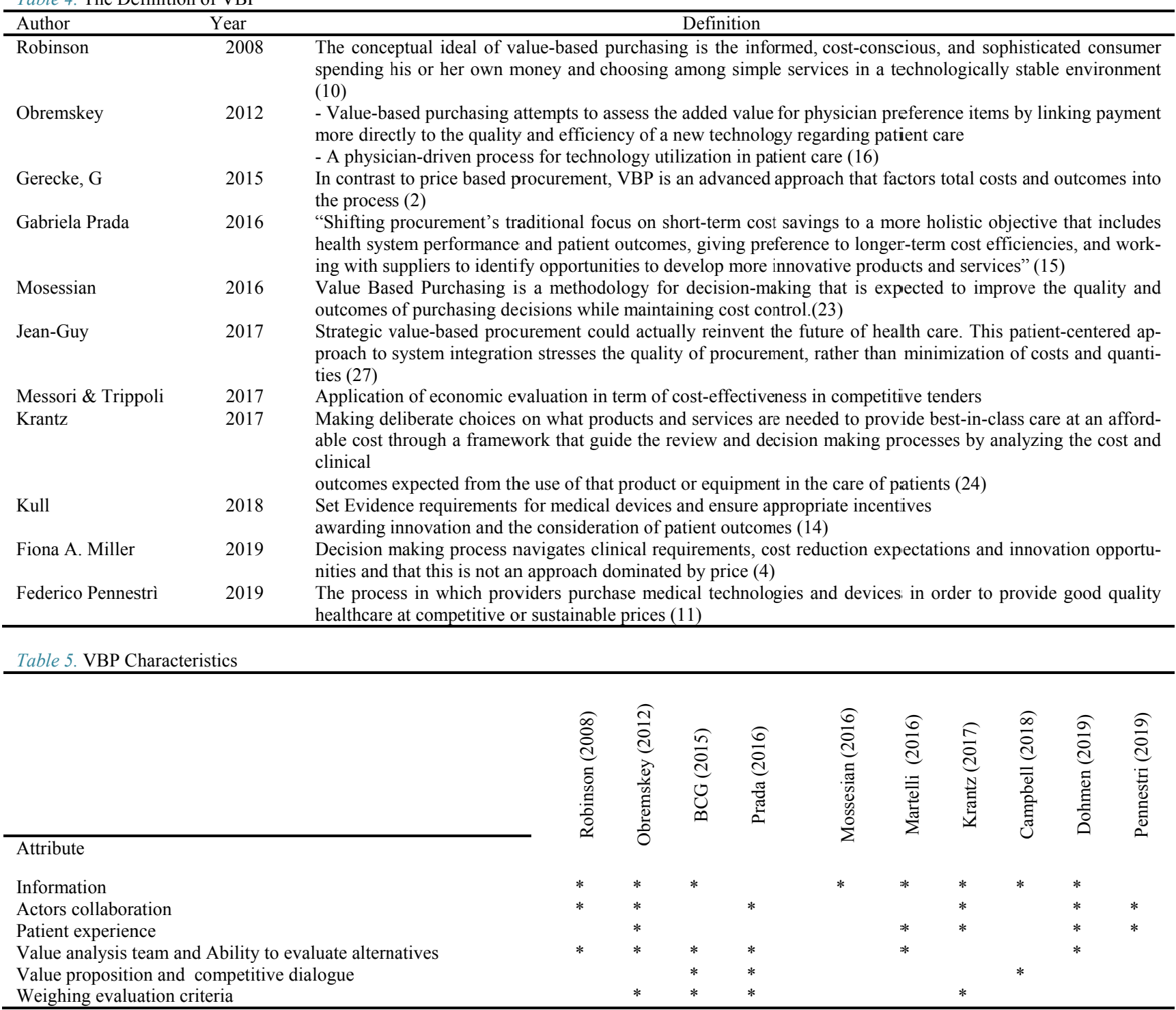




\section{Patient Experience}

The patient is at the core of the evolution of value-based health care (3). According to the definition of VBP, patient participation is an underlying component in improving health care delivery. Patient involvement leads to more credible decisions, better outcomes, and more effective resource allocation (11). There is a major notion towards growing use of patient-related outcome measures and patient-related experience measures in clinical studies of medical devices (28).

\section{Stakeholders Collaboration and Transparent Expecta-} tions

The diversity of stakeholders in the procurement process (providers, suppliers, communities, clinicians, and academics) and their needs and wants complicate the concept of value $(13,18)$, and this is compounded by instability of these needs. VBP needs continuous collaboration among stakeholders (11). The lack of alignment and transparency of expectations of different stakeholders disrupts value creation and increases resource wastage. The most important stakeholders in the procurement of medical devices are physicians, as their preferences play an important role in their selection (22).

\section{Value Analysis Team and the Capacity to Evaluate Op- tions}

To understand the concept of value beyond cost savings, in addition to collaboration and aligning stakeholder expectations, it is necessary to form teams of managers, decision-makers, and clinicians in health care organizations. The main goal of this team is to prioritize needs, collect and standardize information, and prepare request for proposals (RFP) (15). In order to determine the costs and quality of new products, the health system and, in particular, the hospitals must be able to assess and respond to technological change. New technologies should be assessed by a technological review committee to decide if the existing analysis reveals that progress is better than current practices $(10,16,25)$. Also, the health technology assessment (HTA) may be a way to boost the management of medical devices and these teams can run Mini HTAs (4, 9).

\section{Choosing the Right Criteria and Weighting Them}

While new innovations that increase patient quality and/or minimize health care costs can enhance value in our health care system, many emerging technologies remain questionable. Although the lowest price approach may be the most transparent method, the quality criteria are considered only to the extent specified by the procurer. In the new procurement paradigm, it should be possible to evaluate all price and quality criteria, including technical and functional characteristics, and the total cost of the acquisition, which requires the technical competence of the procurer (28). While costs can be measured simply by a variety of methods, defining, identifying, measuring, and analyzing heterogeneous outcome indicators have always been challenging (11). Applying clear and unambiguous metrics of quality, efficiency, and cost that are easy to interpret and operate is crucial in creating a value-based approach. Dimensions that have not yet been considered or under considered (For example, quality-based factors, such as technical merit, accessibility, environmental characteristics, and innovative characteristics) need to be identified, weighed, and used in medical procurement decisions to create a successful bid (15).

\section{Value Proposition and Competitive Dialogue}

A procurement process, which includes a discussion of needs between the parties and a structured value proposition by suppliers, can form success in VBP. A competitive dialogue is a technical term to have a discussion before articulating needs in RFP (25). This action helps to identify and define value expectations and subsequently to have the most appropriate value proposition. Appropriate value proposition consists well-conceived and clearly different relevant claims $(25)$.

\section{Discussion}

Simultaneously improving health outcomes and controlling or reducing costs, or in other words improving the value of health care, has always been a challenge for health systems. Procurement of medical equipment plays a key role in the quality of health services (29) and can be a starting point for a value-based health system. The findings indicated that VBP is a process that is end userdriven based on actual requirements provides higher quality services and organizational performance, addresses issues in cooperation with vendors, and refinements of user-centric services. Any approach that leads to better results at a lower cost will be value based. These approaches should extend the benefits for patients (lower costs and better outcomes), providers (better care efficiencies), payers (stronger cost controls and reduced risks), suppliers (alignment of prices with patient outcomes), and the society (reduced health care spending and better overall health) $(11,30)$.

Recognizing the real need is the starting point of the VBP process. Basically, efficiency and effectiveness is the primary goal of any system; and purchasing medical equipment that is not required challenges the effectiveness of the system. Different criteria usually have to be considered when deciding to buy medical equipment in hospitals $(22,31)$. The greater weight of the price criterion in these decisions is derived from the cost control thinking in the short perspective and cannot guarantee value creation (25). The criteria used in these decisions must be carefully selected (16) and their effect on the final decision must be transparent and ultimately lead to the purchase of the highest quality equipment at a reasonable price (6). Strong and relevant information is the basis of decisions to buy medical devices (32). In addition to clinical data, the information includes details of the various costs $(8,33)$.

An important feature of VBP is a different view of costs rather than prices. Focusing on short-term costs and prices can seriously challenge the creation of value for patients. The difference between the price factor and the cost is that 
the price is a single number, while the cost includes various factors that are relevant to medical devices. These factors include relocation costs, staff training costs, overhead and depreciation costs, software upgrade costs, and contract ancillary costs that must be considered $(2,6)$. VBP of the medical devices considers the cost in the form of the total cost of the ownership of the device and its subsequent costs in the decision-making (26).

Another important aspect of VBP is to consider patients' experiences in decision-making. The patient's understanding of their level of health can complement clinical information; and in some cases, it can even be an alternative (28). Recently, clinical evaluation studies of medical devices have voluntarily considered patients' experiences as an important factor, and this has an increasing trend (28, 34). Patients' experiences have the potential to improve the quality of health care as well as costs. However, its implementation requires scientific frameworks and resources to produce reliable data (34).

Involvement of different people in decision-making is another important point that should be considered. One of the major challenges in the procurement of medical devices is the conflict of interests (10) and organizational barriers $(20,24)$. Historically, physicians have played a major role in purchasing medical devices based on clinical data they have, but in VBP, the emphasis is on decisions by teams and committees (16). These committees bring together different perspectives and capabilities and provide a solution to the aforementioned challenges.

\section{Study Limitations}

The aim of this study was to understand the VBP dialogue in medical devices. Scattering of procurement issues by various health systems made it difficult to retrieve articles, and despite selecting appropriate keywords and checking references, articles that did not explicitly use these keywords may not be retrieved.

\section{Conclusion}

VBP is a framework that guides the review and decision-making to procure a device. The novelty of this approach is the multi-criteria approach to make procurement decisions. In this approach, all dimensions of the value equation (outcome/related costs) must be considered. As mentioned, the cost is seen as the total cost of ownership, and along with other outcome factors, each will have its own weight in the decision. To have VBP, health systems need to work on standardizing information, paying more attention to patients' experiences, identifying stakeholders and their expectations, building data analysis capacity, developing decision criteria, and improving tenders and contracts through value propositions.

\section{Acknowledgment}

The researcher would like to thank Isfahan University of Medical Sciences, for their funding. The present study was approved by the Ethics Committee of Isfahan University of Medical Sciences, Isfahan, Iran, with code IR.MUI.REC.1396.3.909.
Conflict of Interests

The authors declare that they have no competing interests.

\section{References}

1. Porter ME, Teisberg EO. Redefining health care: creating value-based competition on results: Harvard business press; 2006.

2. Gerecke G, Clawson J, Verboven Y. Procurement: the unexpected driver of value-based health care. Boston: Boston Consulting Group. 2015.

3. Porter ME. What is value in health care. NEJM. 2010;363(26):247781.

4. Miller FA, Lehoux P, Peacock S, Rac VE, Neukomm J, Barg C, et al. How Procurement Judges the Value of Medical Technologies: A Review of Healthcare Tenders. Int J Technol Assess Health Care. 2019;35(1):50-5.

5. Messori A, Trippoli S, Marinai C. Handling the procurement of prostheses for total hip replacement: Description of an original value based approach and application to a real-life dataset reported in the UK. BMJ Open. 2017;7(12).

6. Sorenson C, Kanavos P. Medical technology procurement in Europe: A cross-country comparison of current practice and policy. Health Policy. 2011;100(1):43-50.

7. Diaconu K, Chen YF, Cummins C, Moyao GJ, Manaseki-Holland S, Lilford R. Methods for medical device and equipment procurement and prioritization within low-and middle-income countries: findings of a systematic literature review. Glob Health. 2017;13(1):1-16.

8. Innovation N. Value-Based Procurement (VBP) Knowledge, Guide, and Support for All in the Value Chain of Medical Technology. 2017.

9. Trippoli S, Caccese E, Marinai C, Messori A. Value-based procurement of medical devices: Application to devices for mechanical thrombectomy in ischemic stroke. Clin Neurol Neurosurg. 2018;166:61-5.

10. Robinson JC. Value-based purchasing for medical devices. Health Aff. 2008;27(6):1523-31.

11. Pennestrì F, Lippi G, Banfi G. Pay less and spend more-the real value in healthcare procurement. Ann Transl Med. 2019;7(22).

12. Messori A, Trippoli S. Value-based procurement of prostheses for total knee replacement. Orthop Rev. 2017;9(4).

13. Meehan J, Menzies L, Michaelides R. The long shadow of public policy; Barriers to a value-based approach in healthcare procurement. J Purch Supply Manage. 2017;23(4):229-41.

14. Kull S, Atanasov P, Jonas N. Value-based procurement of medical equipment in europe - did the 2014 eu directive influence tendering practices and evidence demand? Vallue Health. 2018:21:S267-S.

15. Prada G, editor Value-based procurement: Canada's healthcare imperative. Healthcare management forum; 2016: SAGE Publications Sage CA: Los Angeles, CA.

16. Obremskey WT, Dail T, Jahangir AA. Value-based purchasing of medical devices. Clin Orthop Relat Res. 2012;470(4):1054-64.

17. Cavlan O, Grey L, Krych A, Llewellyn C, Zerbi C. The European Public-Procurement Opportunity: Delivering Value in Medtech. New York: McKinsey \& Company; 2018.

18. Henshall C, Schuller T. Health te:chnology assessment, value-based decision making, and innovation. Int J Technol Assess Health Care. 2013;29(4):353-9.

19. Arksey H, O'Malley L. Scoping studies: towards a methodological framework. Int J Soc Res Methodol.. 2005;8(1):19-32.

20. Provines $C D$. Overcoming organizational barriers to implementing value-based pricing in the medical devices diagnostics industry. J Med Mark. 2010;10(1):37-44.

21. Sorenson C, Drummond M, Burns LR. Evolving reimbursement and pricing policies for devices in Europe and the United States should encourage greater value. Health Aff. 2013;32(4):788-96.

22. Martelli N, Hansen P, van den Brink H, Boudard A, Cordonnier AL, Devaux C, et al. Combining multi-criteria decision analysis and minihealth technology assessment: A funding decision-support tool for medical devices in a university hospital setting. J Biomed Inform. 2016;59:201-8

23. Mosessian C. Value Based Purchasing: Decision-Making Processes Underlying Hospital Acquisitions of Orthopedic Devices [Sc.D.]. Ann Arbor: University of Southern California; 2016.

24. Krantz H, Strain B, Torzewski J. Medical device innovation and the value analysis process. Surgery. 2017;162(3):471-6. 
25. Campbell B, Campbell M, Dobson L, Higgins J, Dillon B, Marlow $\mathrm{M}$, et al. Assessing the value of innovative medical devices and diagnostics: the importance of clear and relevant claims of benefit. Int J Technol Assess Health Care. 2018;34(4):419-24.

26. Côté J-G, Thomas T, Prada G. Adopting Health Care Innovations in Quebec: Suggested Alternative Models. The Conference Board of Canada; 2017.

27. Adopting Health Care Innovations in Quebec: Suggested Alternative Models. Institut du Québec; 2017.

28. Weszl M, Fanni R, Brodszky V. Is the trend of increasing use of patient-reported outcome measures in medical device studies the sign of shift towards value-based purchasing in Europe? Eur J Health Econ. 2019;20(1):133-40.

29. Lingg M, Wyss K, Durán-Arenas L. Effects of procurement practices on quality of medical device or service received: a qualitative study comparing countries. BMC Health Serv Res. 2016;16(1):1-13.

30. Gray M. Value based healthcare. BMJ-BRIT Med J. 2017.

31. Ivlev I, Kneppo P, Bartak M. Multicriteria decision analysis: a multifaceted approach to medical equipment management. Technol Econ Develop Econ. 2014;20(3):576-89.

32. Tarricone R, Torbica A, Ferre F, Drummond M. Generating appropriate clinical data for value assessment of medical devices: what role does regulation play? Expert Rev Pharmacoecon Outcomes Res. 2014;14(5):707-18.

33. Campillo-Artero C. A full-fledged overhaul is needed for a risk and value-based regulation of medical devices in Europe. Health Policy. 2013;113(1-2):38-44.

34. Squitieri L, Bozic KJ, Pusic AL. The role of patient-reported outcome measures in value-based payment reform. Value Health. 2017;20(6):834-6. 